\title{
REVIEW \\ Heritable symbionts in a world of varying temperature
}

\author{
C Corbin ${ }^{1}$, ER Heyworth ${ }^{2}$, J Ferrari ${ }^{2}$ and GDD Hurst ${ }^{1}$
}

Heritable microbes represent an important component of the biology, ecology and evolution of many plants, animals and fungi, acting as both parasites and partners. In this review, we examine how heritable symbiont-host interactions may alter host thermal tolerance, and how the dynamics of these interactions may more generally be altered by thermal environment. Obligate symbionts, those required by their host, are considered to represent a thermally sensitive weak point for their host, associated with accumulation of deleterious mutations. As such, these symbionts may represent an important determinant of host thermal envelope and spatial distribution. We then examine the varied relationship between thermal environment and the frequency of facultative symbionts that provide ecologically contingent benefits or act as parasites. We note that some facultative symbionts directly alter host thermotolerance. We outline how thermal environment will alter the benefits/costs of infection more widely, and additionally modulate vertical transmission efficiency. Multiple patterns are observed, with symbionts being cold sensitive in some species and heat sensitive in others, with varying and non-coincident thresholds at which phenotype and transmission are ablated. Nevertheless, it is clear that studies aiming to predict ecological and evolutionary dynamics of symbiont-host interactions need to examine the interaction across a range of thermal environments. Finally, we discuss the importance of thermal sensitivity in predicting the success/failure of symbionts to spread into novel species following natural/engineered introduction.

Heredity (2017) 118, 10-20; doi:10.1038/hdy.2016.71; published online 5 October 2016

\section{INTRODUCTION}

Heritable symbionts—-viruses, bacteria, protists or fungal associates that pass from parent to offspring — are found widely in multicellular fungi, plants and animals. It is currently considered that heritable bacteria infect more than half of all arthropod species (Duron et al., 2008), that fungal symbionts are common in both insects and grasses (Clay, 1990; Gibson and Hunter, 2010) and that heritable viruses are widespread in fungi, plants and insects (Roossinck, 2015). Biologically, symbionts such as these represent important modulators of host phenotype and provide heritable variation upon which natural selection acts. Variously, they may provide defence against natural enemies, play a role in host nutrition (through digestive processes, anabolic processes or as farmed symbionts, as in fungal ant gardens) or determine host plant use for insects. These microbes may also modulate the competence of their host for pathogenesis (Bryner and Rigling, 2011) or for vector capability (McMeniman et al., 2012). Maternally inherited symbionts may also act as reproductive parasites, manipulating host reproductive processes towards the production and survival of daughters (Hurst and Frost, 2015). This process is most well recognised in insects, but is also observed in the case of viralinduced male sterility in plants (Grill and Garger, 1981).

The effect of symbiont infection upon host individuals produces further effects at the population and community levels. Sex ratio distorting symbionts affect the reproductive ecology of their host, and may additionally affect population persistence. Those involved in contribution to anabolic function permit their host to exist in nutritional niches that would not otherwise be occupied. Protective symbionts, of course, are likely to impact upon the dynamics of the natural enemies against which they protect (Fenton et al., 2011), and those that affect parasite virulence similarly alter the dynamics of parasite and host. At the community level, plant endophytes alter the pattern of competition between plant species (Clay et al., 1993, 2005; Clay and Holah, 1999), facilitate invasion (Aschehoug et al., 2012) and may change patterns of succession through, for example, reducing herbivory.

In this paper, we examine the sensitivity of these interactions to thermal environment. Thermal environment is well recognised as altering the outcome of host-parasite interactions, both in terms of progression of infection within an individual and in terms of ecological and evolutionary dynamics in populations (Thomas and Blanford, 2003). We examine the thesis that temperature will be an important modulator of heritable symbiont-host interactions. We note that these interactions are distinct from parasite-host comparators in that they may be either beneficial or parasitic, and the symbiont may on occasions be obligatory for survival. We first outline the evidence that obligate heritable symbionts-those required by their host—form a weak link under thermal stress, potentially limiting the geographic range of their host species. We then outline the interaction between thermal environment and facultative heritable microbesmicrobes that are not required, but commonly provide ecologically contingent benefits or act as reproductive parasites or both. We first note heritable symbiont frequency is affected by the magnitude of any benefit they bring to host biology, the physiological cost of carriage of symbionts and the fraction of female offspring that fail to inherit them (segregational loss). We argue that thermal environment affects all of these parameters, and that understanding heritable symbiont dynamics

${ }^{1}$ Institute of Integrative Biology, University of Liverpool, Liverpool, UK and ${ }^{2}$ Department of Biology, University of York, York, UK

Correspondence: Professor GDD Hurst, Institute of Integrative Biology, University of Liverpool, Liverpool L69 7ZB, UK.

E-mail: g.hurst@liv.ac.uk

Received 18 March 2016; revised 19 May 2016; accepted 23 May 2016; published online 5 October 2016 
in natural populations requires detailed study across a range of thermal environments.

\section{OBLIGATE HERITABLE MICROBES COMMONLY REPRESENT A THERMAL 'WEAK LINK' FOR THEIR HOSTS}

There are many animals (and some plants) in which curing an individual of symbionts through antibiotic, heat or other treatments results in the death or sterility of their host. Dependence upon symbionts is commonly observed in insects (Wernegreen, 2002; Zientz et al., 2004), nematodes (Slatko et al., 2010; Darby et al., 2012) and plants (Rodriguez et al., 2009). In many cases these are coadapted metabolic partnerships where the symbiont provides essential nutrients to the host, allowing the exploitation of nutrient-poor resources or habitats (Baumann, 2005; Douglas, 2009). In others, the microbe gives little metabolic contribution to the host, yet the host has evolved to become dependent on the symbiont, as in the wasps Asobara (Dedeine et al., 2001) and Trichogramma (Stouthamer et al., 1990) and the plant Psychotria (Cowles, 1915).

Removal of the obligate symbiont typically results in the death or sterilisation of its host. Many examples of this come from insects, where the obligate symbionts reside in specialised cells known as bacteriocytes (Sacchi et al., 1993; Montllor et al., 2002). Thermal stress commonly causes the death of bacteriocytes that, once killed, do not regenerate. A model for symbiont studies, the aphid-Buchnera aphidicola symbiosis, can be disrupted through exposing the insects to both high (Wilcox et al., 2003; Dunbar et al., 2007) or low temperatures (Parish and Bale, 1991) as the symbiont populations decrease. Indeed, interclonal variation in the thermal sensitivity of aphids is associated with variation in Buchnera, with a singlenucleotide deletion in the heat shock promoter region of the heat shock gene ibpA being associated with reduced tolerance to thermal stress, but improved fitness at normal environmental temperatures (Dunbar et al., 2007; Moran and Yun, 2015). In field cages, aphid clones carrying the reduced heat tolerance strain of Buchnera outcompete clones carrying the tolerant strain at low temperatures, but these clones are outcompeted where heat shocks occur (Harmon et al., 2009). Heat treatments in weevils (Heddi et al., 1999) and cockroaches (Sacchi et al., 1993) kill their bacteriocytes in a similar manner. Mealybug symbionts are also killed at elevated temperature, though this only has an impact on survival/fertility if it occurs during preadult development (Parkinson et al., 2014).

There are strong evolutionary reasons to believe thermal impacts on obligate symbiont function will be general and widespread. These obligate symbionts are vertically transmitted from the parent to offspring with high fidelity (Bandi et al., 1998; Faeth and Fagan, 2002; Hosokawa et al., 2006, 2012). Indeed, obligate symbionts infecting hosts such as aphids (Shigenobu and Stern, 2013), tsetse flies (Akman et al., 2002), cockroaches (Patiño-Navarrete et al., 2013) and nematodes (Slatko et al., 2010) form close partnerships that have lasted for many millions of years, with congruent host and symbiont phylogenies indicating horizontal transmission of the symbiont is rare. This long coevolution within the protective confines of a host has led to a Muller's ratchet process in the symbiont in which there is accumulation of mildly deleterious mutations, alongside large reductions in genome size as loss of nonessential genes occurs over time (Moran, 1996; Nikoh et al., 2011). The process is likely to lead to the degradation of any systems not under strong selection, such as occasional exposure to high temperature.

The process of mutational decay has a major impact upon thermal tolerance. For instance, extensive genome reduction in Buchnera is reflected in this symbiont producing just 5 heat shock proteins, a substantial decrease compared with the 75 produced by its free-living and more thermotolerant relative Escherichia coli (Bronikowski et al., 2001; Wilcox et al., 2003; Pérez-Brocal et al., 2006; Liu et al., 2012). More widely, accumulation of deleterious mutations in remaining genes (Moran, 1996) is reflected in weaker secondary and tertiary structure of proteins in Buchnera (van Ham et al., 2003), with the result that the function of proteins in obligate symbionts is disproportionately impaired at elevated temperatures compared with proteins encoded in the host genome. It is also notable that chaperonin genes-that stabilise protein structure under stress-are highly expressed in obligate symbionts at normal temperature. GroEL, for instance, comprises $\sim 10 \%$ and $6 \%$ of the proteome of Buchnera in aphids and Blochmannia in ants, respectively, in normal thermal environments (Baumann et al., 1996; Fan et al., 2013). More widely, chaperonins represent $22 \%$ of protein abundance in Buchnera and $15 \%$ in Blochmannia. This high level of chaperonin expression is hypothesised to represent a means to cosset proteins that are structurally weak that then fail at elevated temperatures where no further failsafe is possible (Moran, 1996).

The inability of symbionts to cope with temperature stress makes many obligate symbionts into a 'weak link' in host thermal tolerance. Although the services provided by heritable microbes have been credited with allowing early host range expansion by permitting the exploitation of widespread but nutritionally poor resources (Feldhaar and Gross, 2009; Hansen and Moran, 2011), their narrow temperature requirements have been implicated in restricting host spread. Insects such as aphids may be limited to temperate regions by their intracellular symbionts (Dixon et al., 1987), whereas funguscultivating ants are restricted to tropical environments by the temperature requirements of their obligate cold-susceptible fungal symbiont (Mueller et al., 2011). To date, there has been no formal comparative test of this hypothesis, in which thermal niche breadth of hosts with and without symbionts are compared. What is clear, however, is that as global temperatures rise (Cox et al., 2000), plants and animals may be required to move ranges to maintain their ideal environment or to adapt to higher temperatures (Walther et al., 2002; Parmesan and Yohe, 2003). The small genomes and lack of horizontal gene transfer in obligate symbionts (O'Fallon, 2008) may mean that the latter process of adaptation is likely to be barred, thus requiring the host to move range rather than adapting in situ.

\section{THE INTERACTION BETWEEN THERMAL ENVIRONMENT AND FACULTATIVE HERITABLE SYMBIONTS}

Facultative heritable symbionts are those where cured host individuals retain reproduction and fertility. Commonly, bacterial and fungal symbionts are heritable through the female line (but see Moran and Dunbar, 2006; Watanabe et al., 2014), whereas viruses are heritable through both parents, although commonly with higher efficiency through egg than sperm. For maternally inherited agents, their capacity to invade populations depends on their impact on the production, survival and reproduction of female hosts. Minimal models of heritable microbe dynamics thus include two parameters, whose temperature sensitivity will then determine response to thermal environment:

(1) The effects the symbiont has upon host fecundity, survival or sex ratio.

(2) The vertical transmission efficiency of the symbiont (separated into paternal and maternal components for biparentally inherited agents). 
Under this minimal model, a maternally inherited symbiont will spread if, when rare, an infected female leaves on average more infected daughters than an uninfected female leaves daughters. Where the magnitude of improvement in host fecundity/survival/sex ratio is low (that is, an infected female on average leaves a few more infected daughters than an uninfected female leaves daughters), equilibrium prevalence becomes very sensitive to changes in vertical transmission efficiency (Jaenike, 2009; Gundel et al., 2011).

Symbiont-mediated phenotypes that enable facultative heritable microbes to invade populations are very diverse. Some symbionts are reproductive parasites that spread through biasing sex allocation to the production of daughters or inducing incompatibility in uninfected zygotes (Werren et al., 2008). Other interactions are mutualistic and involve benefits to their host that are ecologically contingent-they exist only under particular circumstances, with hosts retaining full function in the absence of symbionts outside these conditions. Symbionts can provide protection from natural enemies (Kellner, 2002; Oliver et al., 2005; Scarborough et al., 2005; Xie et al., 2010; Nakabachi et al., 2013) and disease (Caragata et al., 2013), enhance immune response (Márquez et al., 2007; de Souza et al., 2009) or determine plant host range. They may also be used in offence, as is the case for Photorhabdus released from entomopathogenic nematodes into insects on infection, and which then kill the insect (Poinar, 1975). Biparentally inherited agents may also be mutualists, but a positive effect on their host is not necessary for them to invade a population (L'Heritier, 1970; Fine, 1975).

What then are the likely impacts of thermal environment on the population biology of heritable microbes in natural populations? Associative studies, linking seasonal and spatial variation in symbiont frequency, are limited in power to detect thermal impacts by the presence of multiple covarying factors in natural populations (for example, thermal environment and desiccation) and the presence of spatially varying coevolution. Clinal variation in symbiont prevalence is a more powerful indicator of thermal environment driving symbiont dynamics, and does support temperature-symbiont interactions in a number of cases (Table 1). However, these data have multiple potential sources for the association. Thus, a more precise view can be gained through defined experimental study. At its most powerful, this may involve varying thermal environment within laboratory or caged populations over a number of generations and examining its impact on symbiont dynamics. For instance, Versace et al. (2014) noted that the Wolbachia strain that spread in passage through
Drosophila melanogaster population cages depended upon the temperature at which the population was maintained (Versace et al., 2014). However, studies such as this are logistically complex for many species. More common are single-generation studies that examine one or more aspects of the host-symbiont interaction under different temperatures. Below we summarise these studies. We first outline evidence that indicate heritable symbionts may directly alter host thermal tolerance. We then outline how phenotypes providing ecologically contingent benefits to their host and reproductive manipulation phenotypes are altered by thermal environment. We then examine data with respect to temperature impacts upon vertical transmission and the direct physiological cost of symbiont infection. We draw this information together to create a generalised picture of the thermal sensitivity of heritable microbe-host interactions.

\section{Direct effects of symbiont presence on host thermal tolerance}

Laboratory study indicates that facultative heritable bacteria can affect host thermal tolerance in a number of cases. In aphids, at least three different facultative symbionts increase insect survival or reproduction after heat shock (Chen et al., 2000; Russell and Moran, 2006; Heyworth and Ferrari, 2015). Hamiltonella infections in whitefly confer a similar protection (Brumin et al., 2011). The mechanisms behind symbiont-conferred increase in thermal tolerance are not always known, although there are several hypotheses. The ability of Serratia symbiotica to permit pea aphids to survive at high temperatures was hypothesised to be due to Serratia replacing the amino acid biosynthesis function of the obligate symbiont Buchnera (Koga et al., 2003, 2007), but Burke and Moran (2011) noted S. symbiotica is incapable of this because of deletion or degradation of amino acid biosynthesis pathways, and indeed it may itself be dependent on Buchnera. Instead, it seems that Serratia protects Buchnera, possibly by lysing to release metabolites (Montllor et al., 2002; Burke et al., 2010). Meanwhile in whitefly, the presence of the facultative symbiont increases expression of host-produced stress genes, inadvertently preparing it for thermal stress (Brumin et al., 2011).

Heritable fungal endophytes also impact upon plant heat stress adaptation (Rodriguez and Redman, 2008; Rodriguez et al., 2009). Most notably, endophytes of panic grass permit plant growth on geothermal soils in Yellowstone National Park (Redman et al., 2002; Rodriguez et al., 2008). This is a mutualistic relationship, as in some cases neither plant nor fungus can survive the high temperature without the other (Redman et al., 2002; Márquez et al., 2007).

Table 1 Studies showing geographical variation in symbiont prevalence that may be attributable to temperature differences

\begin{tabular}{|c|c|c|c|c|}
\hline Host & Symbiont & Locality & Pattern & References \\
\hline Acyrthosiphon pisum & Regiella insecticola & Japan & $\begin{array}{l}\text { Higher prevalence in colder north and east. Significant correlation with } \\
\text { temperature, as well as precipitation and host plant. There was no } \\
\text { temperature correlation for Serratia, Rickettsia or Spiroplasma, though } \\
\text { the latter two are found only in the southwest at low frequency. }\end{array}$ & Tsuchida et al. (2002) \\
\hline Adalia bipunctata & Spiroplasma & Sweden & $\begin{array}{l}\text { Spiroplasma absent north of } 63^{\circ} \mathrm{N} \text { in } 2011-2013 \text {. The northernmost } \\
\text { limit was } 61^{\circ} \mathrm{N} \text { in } 2000-2002 .\end{array}$ & Tinsley (2003); Pastok (2015) \\
\hline Culicoides imicola & Cardinium & Israel & $\begin{array}{l}\text { Prevalence declines with increasing maximum daytime temperature in } \\
\text { locality and increases with increasing minimum night-time temperature. }\end{array}$ & Morag et al. (2012) \\
\hline Curculio sikkimensis & $\begin{array}{l}\text { Sodalis, Rickettsia } \\
\text { and Wolbachia }\end{array}$ & Japan & $\begin{array}{l}\text { Higher prevalence of three symbionts in warmer areas to the southwest. } \\
\text { Significant correlation with temperature. No correlation for Spiroplasma. }\end{array}$ & Toju and Fukatsu (2011) \\
\hline Drosophila melanogaster & Wolbachia & Eastern Australia & $\begin{array}{l}\text { Higher prevalence in tropical regions of Australia compared with } \\
\text { subtropical and temperate regions. Pattern stable over } 20 \text { years. Similar, } \\
\text { weaker pattern observed in North America. }\end{array}$ & $\begin{array}{l}\text { Hoffmann et al. (1986); } \\
\text { Kriesner et al. (2016) }\end{array}$ \\
\hline
\end{tabular}


Fascinatingly, the heat tolerance property is determined by a viral heritable symbiont of the endophyte fungus, with the presence of the virus enabling both endophyte and plant persistence. Further to this, endophytes may increase seed germination under thermal stress (Hubbard et al., 2012).

To date, the majority of studies of heritable symbiont impacts on thermal tolerance have investigated the impacts of elevated temperature. We found a single study examining frost resistance in relationship to heritable symbionts in insects, and this revealed no impact of symbiont presence on frost tolerance (Lukasik et al., 2011). However, the presence of nonheritable symbionts with freeze-tolerance phenotypes suggests that similar phenotypes warrant more extensive examination for heritable microbe-host interactions. Anaplasma phagocytophilum is acquired horizontally each generation by its tick host Ixodes scapularis following blood feeding. Observations and experiments indicate that Anaplasma infection protects its host against damage from frost and cold. This occurs through Anaplasma-induced induction of anti-freeze protein production by the host individual (Neelakanta et al., 2010). Further to this, nonheritable Spiroplasma infections increase corn leafhopper survival during overwintering periods (Ebbert and Nault, 1994), indicating there may be impacts of symbionts on overwinter (freeze) survival.

\section{Impact of temperature on ecologically contingent benefits}

We found two studies relating the impact of temperature on protective phenotype in natural infections of insects. In the European beewolf Philanthus triangulum, Streptomyces heritable symbionts secrete antibiotics that protect the host cocoon from pathogen attack during diapause in the soil. Koehler and Kaltenpoth (2013) found thermal environment (from 15 to $25^{\circ} \mathrm{C}$ including diurnal variation) had no impact on the quantity of antibiotic produced. In contrast to this, pea aphids carrying Hamiltonella defensa were nearly completely resistant to attack by Aphidius ervi parasitic wasps at $20^{\circ} \mathrm{C}$, but were susceptible at 25 and $30^{\circ} \mathrm{C}$, postulated to represent thermal sensitivity of symbiont-mediated protection (Bensadia et al., 2006; Guay et al., 2009). Further work confirmed this result, but additionally showed protection was insensitive to temperature in clones where $H$. defensa co-occurred with PAXS (Guay et al., 2009). Although this would have an impact upon symbiont dynamics, the role of host and symbiont factors in establishing this pattern were not ascertained.

Outside of heritable microbe interactions with insects, temperature modulates the effect of heritable virus infection in the chestnut blight fungus Cryphonectria parasitica. In this interaction, viral presence commonly alters fungal growth and sporulation in vitro, and produces a hypovirulent phenotype when the fungus is introduced to the chestnut tree. The hypovirulent phenotype associated with virus presence is temperature sensitive, commonly greatest at $24^{\circ} \mathrm{C}$, as compared with 12,18 and $30^{\circ} \mathrm{C}$. The authors also noted a fungal and viral genotype dependence of the virulence phenotype, and conclude that the coevolutionary dynamics of the system would thus be determined by a complex $\mathrm{G} \times \mathrm{G} \times \mathrm{E}$ interaction (Bryner and Rigling, 2011)

Studies investigating the impact of thermal environment upon heritable symbiont dynamics have largely focussed on the direct impact of temperature on the phenotype of the symbiont as outlined above. However, the dynamics of heritable microbes may also be altered by changes in the benefit derived from a given phenotype that may be driven by temperature-driven changes in other biotic interactions. For instance, the frequency achieved by a symbiont that protects against natural enemies depends upon the rate of attack by enemies against which the symbiont defends. Thermal environment may alter both individual wasp movement patterns, the density of attackers, their ability to parasitise in the absence of protection and indeed the community of species that do attack. In so doing, it would alter the dynamics of the symbiont even if the transmission and phenotype of the symbiont are temperature invariant. Understanding thermal impacts on this ecological context is a key area for future work.

\section{Impact of temperature on reproductive parasitic phenotypes}

Many studies examine the impact of thermal environment on the expression of reproductive parasitic phenotypes in insects (Table 2). Most commonly, Wolbachia-induced male killing, parthenogenesis induction and cytoplasmic incompatibility are ablated at high temperatures. However, the temperature required for the phenotype to be affected varies - in the temperate species Drosophila bifasciata, male killing becomes incomplete above $23.5^{\circ} \mathrm{C}$ (Hurst et al., 2000, 2001). Cytoplasmic incompatibility (CI) is commonly less strongly expressed at high temperatures, becoming incomplete in D. simulans at $28^{\circ} \mathrm{C}$, and at temperatures of $>30^{\circ} \mathrm{C}$ in other species (Wright and Wang, 1980; Trpis et al., 1981; Stevens, 1989; Clancy and Hoffmann, 1998; Johanowicz and Hoy, 1998; van Opijnen and Breeuwer, 1999). However, there are a number of cases where phenotype is only affected following multigenerational passage at elevated temperatures. There is also evidence that heat shock (exposure to temperatures exceeding $35^{\circ} \mathrm{C}$ for between $30 \mathrm{~min}$ and $2 \mathrm{~h}$ ) alters the expression of CI (Feder et al., 1999). Currently, it is unclear why thermal sensitivity of these traits is so variable, and whether it is associated with host or microbial factors. In contrast to Wolbachia-induced phenotypes, Spiroplasma-induced male killing is ablated at lower temperatures (Williamson, 1965; Counce and Poulson, 1966; Anbutsu et al., 2008).

As previously discussed with respect to the dynamics of protective symbionts, the impact of temperature on symbiont prevalence may also be affected by the effect of the phenotype on host survival and fecundity. For instance, the drive associated with male killing relates to the intensity of sibling-sibling interactions, with male host death having little impact on symbiont fitness when these interactions are weak (for example, food excess), but are strong when siblings strongly compete (for example, food paucity) (Hurst and Frost, 2015). Thus, external ecological characteristics that may be thermally dependent (for example, aphid supply for ladybirds) are likely to impact upon symbiont dynamics. In contrast, the impact of thermal ablation of phenotype on symbiont prevalence is likely to be much lower for traits like CI, where the effect is not strongly ecologically contingent, and which is under positive frequency-dependent selection. Where CI causing Wolbachia are common, nearly all females mate to infected males. If CI strength diminishes by $50 \%$, this remains a very high fitness loss for uninfected females, such that declines in prevalence associated with thermal ablation of phenotype will be small. In contrast, ablation of male killing, which produces only a small (1-20\%) impact on female survival, will have a more profound influence, potentially making the symbiont net costly to female host (measured in terms of production/survival of daughters). Thus, theory predicts the impacts to be greater in this case (Jaenike, 2009).

\section{Physiological cost of symbionts at different temperatures}

Endosymbionts, which rely on their hosts for nutrition, can impose a cost on their host. For example, the defensive symbiont $H$. defensa can be costly to the hosts Acyrthosiphon pisum and Aphis fabae (see, for example, Vorburger et al., 2013; Polin et al., 2014 and references therein). Costs may manifest, or be manifested more 
Table 2 Thermal effects on the phenotypes of natural reproductive parasites of insects

\begin{tabular}{|c|c|c|c|c|c|}
\hline Host & Symbiont & $\begin{array}{l}\text { Nature of } \\
\text { symbiosis }\end{array}$ & Assay type & Impact of temperature on phenotype & Source \\
\hline Aedes polynesiensis & Wolbachia & $\mathrm{Cl}$ & Phenotype, cytology & $\begin{array}{l}\mathrm{Cl} \text { eliminated by } 32-33^{\circ} \mathrm{C} \text { exposure as larvae for } \\
5-7 \text { days. } 30-32{ }^{\circ} \mathrm{C} \text { did not eliminate } \mathrm{Cl} \text {. Larva dies } \\
\text { above } 33^{\circ} \mathrm{C} \text {. }\end{array}$ & Wright and Wang (1980) \\
\hline Drosophila equinoxalis & ESRO Spiroplasma & MK & Phenotype & $\begin{array}{l}\text { MK reduced by embryonic heat treatment with } \\
\text { various temperatures and durations between } 34 \text { and } \\
40^{\circ} \mathrm{C} \text {. }\end{array}$ & Malogolowkin (1959) \\
\hline D. nebulosa & NSRO Spiroplasma & MK & Phenotype, qPCR & $\begin{array}{l}\text { Highly penetrant } \mathrm{MK} \text { at } 25^{\circ} \mathrm{C} \text {. At } 18{ }^{\circ} \mathrm{C} \text {, there is loss } \\
\text { of fully female broods at generation } 2 \text {. At } 28^{\circ} \mathrm{C} \text {, } \\
\text { gradual loss occurs until at generation } 8,1 / 8 \text { strains } \\
\text { show strong female bias. }\end{array}$ & Anbutsu et al. (2008) \\
\hline D. willistoni & WSRO Spiroplasma & MK & Phenotype & $\begin{array}{l}\text { No effect of embryonic heat treatment at various } \\
\text { temperatures and durations between } 34 \text { and } 40^{\circ} \mathrm{C} \text {. }\end{array}$ & Malogolowkin (1959) \\
\hline D. bifasciata & A-group Wolbachia & MK & Phenotype, cytology & Phenotype lost between 23.5 and $25^{\circ} \mathrm{C}$. & Hurst et al. (2000, 2001) \\
\hline D. melanogaster & $\begin{array}{l}\text { wMelPop Wolbachia } \\
\text { (may not exist in wild) }\end{array}$ & $\begin{array}{l}\text { Premature } \\
\text { host death }\end{array}$ & Phenotype & $\begin{array}{l}\text { No mortality effect at } 19^{\circ} \mathrm{C} \text {. At } 25^{\circ} \mathrm{C} \text {, wMelPop } \\
\text { induces early mortality, with effect increasing } \\
\text { at } 29^{\circ} \mathrm{C} \text {. }\end{array}$ & $\begin{array}{l}\text { Min and Benzer (1997); } \\
\text { Reynolds et al. (2003) }\end{array}$ \\
\hline D. simulans & wRi Wolbachia & $\mathrm{Cl}$ & Phenotype, cytology & $\begin{array}{l}\text { Ageing and rearing males at elevated temperature } \\
\left(27^{\circ} \mathrm{C}\right) \text { reduces incompatibility; larval thermal } \\
\text { environment critical. }\end{array}$ & Clancy and Hoffmann (1998) \\
\hline D. simulans & Wolbachia & $\mathrm{Cl}$ & Phenotype & $\begin{array}{l}\mathrm{Cl} \text { suppressed in crosses between two unidirection- } \\
\text { ally incompatible fly strains exposed to } 28^{\circ} \mathrm{C} \text { in } \\
\text { early life. }\end{array}$ & Hoffmann et al. (1986) \\
\hline D. simulans & Wolbachia & $\mathrm{Cl}$ & Phenotype & $\begin{array}{l}\text { Larval heat shock at } 36{ }^{\circ} \mathrm{C}(1 \mathrm{~h}) \text { reduced } \mathrm{Cl} \text { in adult } \\
\text { male flies. Egg mortality was } 90 \% \text { rather than } 45 \% \text {. } \\
\text { Heat shock did not influence survival or fertility. }\end{array}$ & Feder et al. (1999) \\
\hline Nasonia vitripennis & Wolbachia strain A & $\mathrm{Cl}$ & Phenotype, qPCR & $\begin{array}{l}\text { Positive correlation between density and } \mathrm{Cl} \\
\text { penetrance within temperature groups. However, } \\
\text { density and } \mathrm{Cl} \text { were decoupled between groups. } \\
\text { Temperature may change the density threshold } \\
\text { required for } \mathrm{Cl} \text {. }\end{array}$ & $\begin{array}{l}\text { Bordenstein and } \\
\text { Bordenstein (2011) }\end{array}$ \\
\hline Ostrinia scapulalis & Wolbachia & MK & Phenotype, PCR & $\begin{array}{l}\text { Exposing larval female moths to } 63^{\circ} \mathrm{C} \text { for } \\
20-30 \text { min suppresses phenotype. } 40 \text { min has a } \\
\text { greater effect but causes high lethality. } 53^{\circ} \mathrm{C} \text { not } \\
\text { efficient at nonlethal exposure times. } 34-38^{\circ} \mathrm{C} \text { for } \\
\text { long periods does not fully suppress } \mathrm{MK} \text {. }\end{array}$ & $\begin{array}{l}\text { Sakamoto et al. (2008); } \\
\text { Sugimoto et al. (2015) }\end{array}$ \\
\hline Tribolium confusum & Wolbachia & $\mathrm{Cl}$ & Phenotype & $\begin{array}{l}\text { Suppression of } \mathrm{Cl} \text { with exposure to } 37^{\circ} \mathrm{C} \text { for } 12 \text { days } \\
\text { in larval stage. Number of individuals lacking the } \\
\text { phenotype increases with exposure time. }\end{array}$ & Stevens (1989) \\
\hline Trichogramma cordubensis & Wolbachia & $\begin{array}{l}\text { Induces } \\
\text { thelytoky }\end{array}$ & $\begin{array}{l}\text { Phenotype with } \\
\text { 'permissive passage' }\end{array}$ & $\begin{array}{l}\text { Thelytoky reduced over } 4 \text { generations at } 30^{\circ} \mathrm{C} \text {, } \\
\text { significant during generations } 2-4 \text {. Recovery with } \\
4 \text { generations of passage at } 23^{\circ} \mathrm{C} \text {. }\end{array}$ & $\begin{array}{l}\text { Girin and Boulétreau (1995); } \\
\text { Pintureau et al. (1999) }\end{array}$ \\
\hline Tetranychus urticae & Wolbachia & $\mathrm{Cl}$ & $\begin{array}{l}\text { Phenotype, PCR } \\
\text { with 'permissive } \\
\text { passage' }\end{array}$ & $\begin{array}{l}\text { High loss of phenotype after } 4 \text { generations at } 32{ }^{\circ} \mathrm{C} \\
\text { (threshold at } 31-32{ }^{\circ} \mathrm{C} \text { ). Development time was } \\
\text { reduced, and many heat-cured lines died out. }\end{array}$ & $\begin{array}{l}\text { van Opijnen and Breeuwer } \\
\text { (1999) }\end{array}$ \\
\hline
\end{tabular}

Abbreviations: $\mathrm{Cl}$, cytoplasmic incompatibility; MK, male killing; qPCR, quantitative PCR.

In 'Assay type' details, Phenotype is strength of phenotype measured; qPCR, PCR, cytology and Southern hybridization are means by which symbiont presence was confirmed; and permissive passage is test for symbiont presence conducted after recovering the lineage to standard thermal environment.

dramatically, when the host is under physiological stress. Thus far, there have been few studies examining the physiological cost of symbionts at different temperatures. In A. pisum, the endosymbiont Regiella insecticola was found to be costly under heat stress, but not when hosts were reared in standard conditions. The cost was observed after 2-day-old nymphs were exposed to a period of heat shock at $37.5^{\circ} \mathrm{C}$. Uninfected heat-shocked aphids were $24 \%$ more likely to survive to adulthood than infected heat-shocked aphids, and infected heat-shocked aphids also suffered higher sterility rates (Russell and Moran, 2006).
Study of Wolbachia-infected D. melanogaster also indicates thermal impacts on the cost of carrying a symbiont. D. melanogaster were established in field cages in tropical and temperate areas of Australia during winter. Wolbachia effect on the host, relative to uninfected flies, depended on whether the fruit fly nuclear background was tropical or temperate. In tropical cages, infected flies of both backgrounds had lower fecundity than their uninfected counterparts. In contrast, in the temperate cage, the effects of Wolbachia depended on the nuclear background, with temperate-background flies experiencing higher 
fecundity when infected. This example demonstrates that a previously beneficial symbiont might become a liability when local climate is unfavourable (Olsen et al., 2001). More recently, Kriesner et al. (2016) demonstrated that Wolbachia has a particular negative impact upon fecundity in flies that survive through winter. Flies with Wolbachia post dormancy have a lower fecundity than flies without the infection (Kriesner et al., 2016).

Outside of insect-bacterium interactions, temperature dependence of heritable viral impacts on fungal growth in vitro has also been reported in a number of interactions (see, for example, Hyder et al., 2013 and references therein). Furthermore, Sigma virus in D. melanogaster causes a deleterious $\mathrm{CO}_{2}$ sensitivity that is highest at low temperatures, with reduced concentrations required to induce death (see Longdon et al., 2012 and references therein). Thus, it seems that viral as well as bacterial symbionts show temperature-dependent phenotypes in multiple host species.

\section{Thermal environment and transmission efficiency}

Studies of heritable bacteria in insects have concluded that vertical transmission efficiency is sensitive to rearing temperature (Table 3). In a manner similar to that observed for phenotype, Wolbachia vertical transmission efficiency has been observed to be reduced at raised temperature, and Spiroplasma vertical transmission efficiency reduced at cool temperatures. However, it is notable that phenotype expression is commonly more sensitive than transmission, with phenotype ablation occurring before loss of vertical transmission in a number of cases.

Few studies examine the impact of overwintering on heritable symbiont transmission. Perrot-Minnot et al. (1996) note that segregational loss of Wolbachia is increased during artificially prolonged (2-6 year) larval diapause. In pea aphids, $R$. insecticola shows segregational loss in sexually produced eggs that persist through winter, but $100 \%$ vertical transmission in asexual summer reproduction (Moran and Dunbar, 2006). These observations raise the potential importance of overwinter phases on symbiont transmission, but this requires evaluation over natural diapause periods across a number of symbioses.

One caveat to studies of transmission efficiency is the degree to which we can accurately score infected and uninfected individuals in a standard PCR assay. This is an issue of detectability of low titre infections. For instance, van Opijnen and Breeuwer (1999) studied the impact of high temperature $\left(32^{\circ} \mathrm{C}\right)$ passage of laboratory stocks of the red spider mite Tetranychus urticae upon the presence of Wolbachia. PCR assays were used to detect Wolbachia infection, and indicated that prevalence decreased over four generations of exposure to this temperature, with no individual scored as infected in generation 4 . However, Wolbachia infection was detected in $29 \%$ of individuals two generations after restoration of these lines to $25^{\circ} \mathrm{C}$, the permissive temperature. Only after six generations of exposure to $32^{\circ} \mathrm{C}$ was Wolbachia found to be lost after restoration to the permissive temperature (van Opijnen and Breeuwer, 1999). The most parsimonious explanation for these data is that the symbiont declined in titre during passage, and by generation 4 the titre was sufficiently low that it was undetectable by the PCR methodology used. Care should thus be taken to either use a recovery period before concluding symbiont absence (see examples in Table 3) or using very stringent quality control with respect to symbiont detectability in PCR assays. Such assays could involve 'spiking' of symbiont-carrying material at varying dilutions into uninfected carrier host DNA to establish the limit to detectability, and also employ quantitative PCR to robustly determine limits to detection.
Outside insect-heritable bacteria interactions, it is known that transmission of sigma virus in D. melanogaster is thermally sensitive. Vertical transmission is ablated at high temperatures, with $30^{\circ} \mathrm{C}$ passage curing flies. In plants, fungal endophyte vertical transmission in cool season grasses is also known to be affected by temperature. Endophyte fungi commonly transfer on the exterior of seeds. Do Valle Ribeiro (1993) reviewed the impact of seed storage conditions on the survival of the fungus and its propagation following germination. They concluded that storage time, humidity and temperature of storage affected the likelihood of plants germinating from seeds acquiring the symbiont. Overall, seeds maintained at higher temperatures, at low relative humidity and for longer periods of time were less likely to retain the infection, presumably associated with loss of fungal viability on the seed (do Valle Ribeiro, 1993). However, the impact of temperature is not universal: Oldrup et al. (2010) noted that $80 \%$ of locoweed seed maintained in uncontrolled warehouse conditions over 40 years retain Undifilum endophyte infection (Oldrup et al., 2010).

Variation in vertical transmission efficiency is thought to be an important driver of endophyte dynamics and equilibrium prevalence, as the 'benefit' from endophyte infection is relatively weak (Afkhami and Rudgers, 2008; Gundel et al., 2008). However, although loss in seed storage argues for a role of temperature in endophyte dynamics, exploration of the whole transmission cycle under natural conditions is required to determine the sensitivity of endophyte dynamics to thermal environment: loss of endophyte infection can occur at any of three stages-from tiller to seed, seed to seedling and during tiller growth (Afkhami and Rudgers, 2008). These authors conclude that vertical transmission variation may be important in determining intraspecific spatial and interspecies differences in endophyte prevalence, and the role of the environment in generating vertical transmission variation warranted investigation. However, they note that variation in transmission and prevalence of infection may be additionally associated with the frequency with which the drought tolerance phenotype is induced (Davitt et al., 2011), or may derive from coevolutionary interactions between host and fungus affecting transmission efficiency.

\section{A GENERALISED VIEW OF THERMAL IMPACTS ON FACULTATIVE HERITABLE SYMBIONTS}

The above account creates a few clear messages. The first of these is that many aspects of heritable symbiont phenotype and transmission are thermally sensitive. Although our review is biased to heritable bacteria-insect interactions, thermal sensitivity was noted in a wide range of interactions (bacteria-insect, fungus-plant, virus-plant, virus-insect), and is likely to be general. However, the pattern of thermal sensitivity (chill vs heat; threshold for thermal impact) varies greatly across interactions. Thus, it is clear that although thermal environment is very likely to affect facultative symbiont dynamics in many systems, the way in which it does so will vary greatly.

A second observation is that different aspects of the host-symbiont interaction have different thermal sensitivities. One commonly measured 'linking' variable is symbiont titre-the number of symbionts resident in a host. Thermal environment impacts upon titre, and phenotype ablation and segregational loss during reproduction is commonly associated with low titre. Commonly, phenotype ablation occurs before high levels of segregational loss, as attested by the recovery of phenotypes after passage through permissive temperature regimes. Indeed, studies of paternal inheritance of bacterial symbionts indicate as few as four bacterial cells are sufficient to establish infection in the new generation (Watanabe et al., 2014). 
Table 3 Thermal effects on the vertical transmission of natural bacterial symbionts of insects

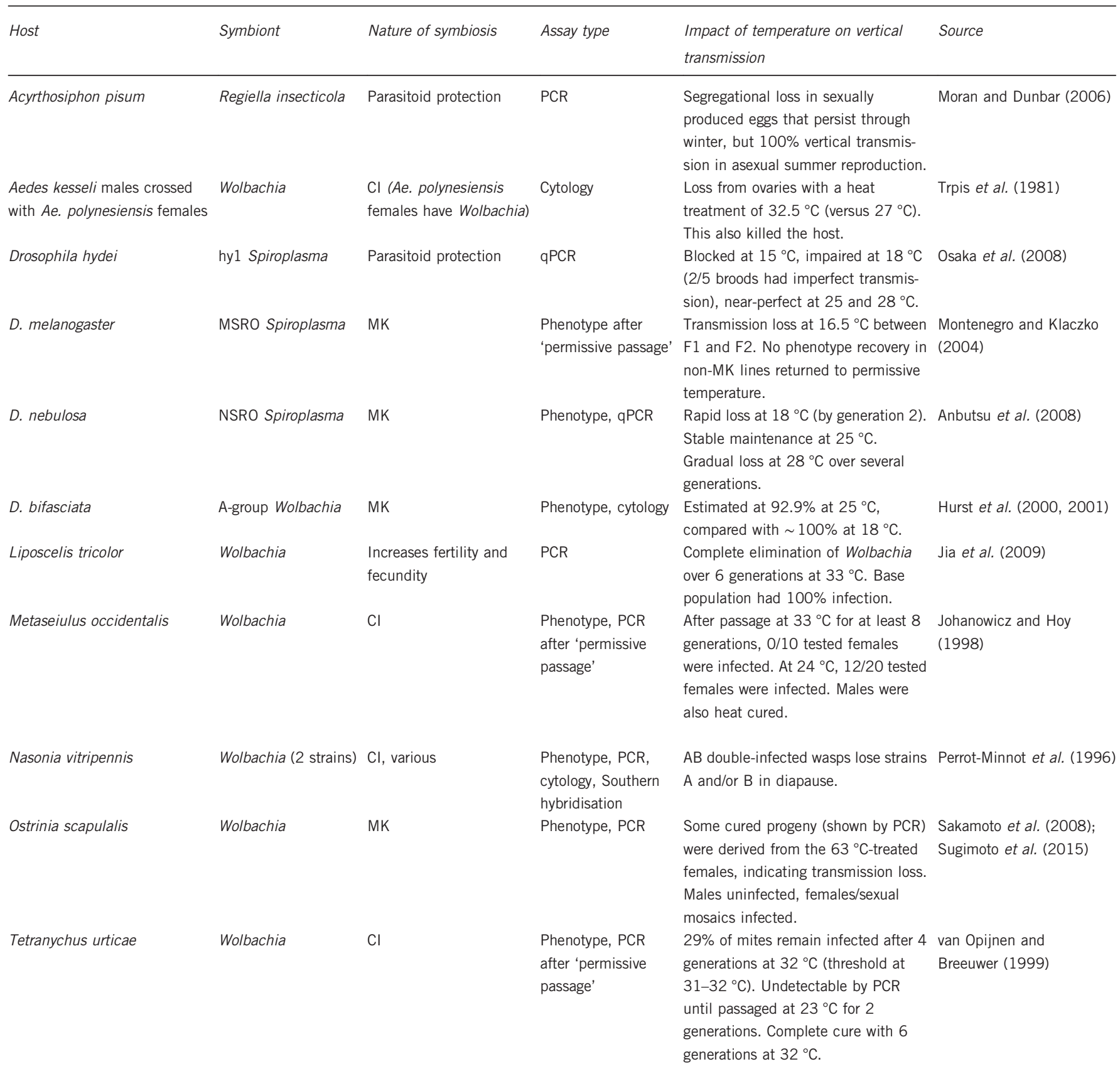

Abbreviations: $\mathrm{Cl}$, cytoplasmic incompatibility; MK, male killing; qPCR, quantitative PCR.

In 'Assay type' details, Phenotype is detection of symbiont through presence of its phenotypic effect; qPCR, PCR, cytology and Southern hybridization are other means by which symbiont presence was confirmed; and permissive passage is test for symbiont presence conducted after recovering the lineage to standard thermal environment.

The underpinning of phenotype and transmission by titre is important as it indicates that the impact of thermal environment is not simply associated with the current thermal regime, but will have strong historical influences (see, for example, Jaenike, 2009). Temperature previously experienced in life impacts upon current titre, and thus on the expression of phenotype and vertical transmission rate. Indeed, thermal impacts in a number of systems have been shown to be transgenerational, with symbioses taking a number of generations to recover to maximum expression following return to the permissive temperature. An important property of a symbiont-host interaction, therefore, is the rate at which symbiont titre is affected by temperature, both in terms of reduction and recovery. A practical consequence of this short-term evolution is that laboratory passage conditions may produce rather rapid changes in this aspect of host biology. For Drosophila, the simple act of maintaining a Spiroplasma stock at $18^{\circ} \mathrm{C}$ may cure the host of heritable symbiont infection. Changing thermal environment may more subtly alter symbiont titre in other cases that may take time to recover. Overall, the heritable symbiont element of a host may be inadvertently (and in the case of curing) permanently altered by simply placing stocks at a different temperature during 
maintenance, or during an experiment. The heritable symbiont component of an organism is much less fixed in the creation of isofemale lineages than is nuclear genetic variation.

The centrality of titre in expression of phenotype and vertical transmission further suggests that thermal sensitivity of host-symbiont interactions may affect the success/failure of heritable symbionts in novel host species. Facultative symbiont incidence in host communities is partly a function of their movement into, and subsequent propagation through, new host species (Zug et al., 2012; Longdon et al., 2014). Furthermore, Wolbachia transinfected into novel host species is in applied usage as a means to interrupt vector competence of focal species. It is notable that when symbionts are placed into novel hosts they may attain a different titre from the native host (Kageyama et al., 2006), and this is likely to be reflected in changes to the thermal sensitivity of the host-symbiont interaction. Thermal sensitivity of phenotype in novel hosts has been investigated in two mosquito species transinfected with Wolbachia from D. melanogaster as a means of altering vector competence. Studies show that the impact of wMel on reducing Aedes aegypti competence for dengue virus transmission is insensitive to environmental temperature (Ye et al., 2016). In contrast, the impact of Wolbachia strain wAlbB on Plasmodium proliferation in An. stephensi is temperature sensitive (Murdock et al., 2014). wAlbB reduced mosquito potential to transmit Plasmodium at $28^{\circ} \mathrm{C}$ but had no effect at either 20 or $24^{\circ} \mathrm{C}$. Thus, although focal traits can be robust to thermal variation on transinfection, this characteristic must be determined on a case-by-case basis, and this is an important biosafety and efficacy consideration with respect to releases. It also indicates that temperature may affect the ability of an infection to propagate through a novel host species

Overall, linking laboratory measures with field data remains a challenge. In part, this is because (as discussed above) impacts can be historical. As noted previously, the presence of latitudinal clines in symbiont prevalence in focal species supports a link between thermal environment and symbiont dynamics in nature (Table 1). Furthermore, broad between-species surveys indicate latitudinal patterns that indicate general patterns. For instance, Wolbachia is generally rare in butterflies from high latitudes, both in terms of more commonly being absent, and where present, more commonly being at low prevalence (Ahmed et al., 2015). Determining the role of thermal environment in creating these patterns is complicated by temperature being one of a number of abiotic, biotic and coevolutionary factors that affect symbiont-host dynamics. There are, however, examples where the pattern is consistent with experimental data. For instance, Wolbachia in D. melanogaster is costly in the context of overwintering, and Wolbachia is less common in temperate populations than tropical populations of this species. For male-killing Spiroplasma in Drosophila, experiments indicate symbiont phenotype and vertical transmission are ablated at low temperatures. Consistent with this, male-killing Spiroplasma are recorded commonly in drosophilids from tropical biomes (Williamson and Poulson, 1979; Montenegro et al., 2005, 2006; Pool et al., 2006), but not in temperate species/temperate parts of species range (see Haselkorn, 2010). This is unlikely to be a study bias, as male-killing Wolbachia have been isolated from temperate flies following observation of female-biased sex ratios produced by individual females (Hurst et al., 2000; Sheeley and McAllister, 2009; Unckless and Jaenike, 2012). Furthermore, although male-killing Spiroplasma strains have been isolated from South American and Sub-Saharan African D. melanogaster, no records exist from D. melanogaster from temperate biomes. Given that the intensity of collection and study is biased toward temperate collection, it is fair to conclude that male-killing Spiroplasma show a tropical bias in
Drosophila, consistent with the observed thermal sensitivity of this symbiotic interaction.

The review above also highlights a variety of areas for future study. The impact of overwintering environment on symbiont survival, and reciprocally of symbionts on host survival overwinter, are both very poorly researched. There are good reasons (outlined above) to believe diapause/overwinter period may be an important contributor to symbiont dynamics, and these factors should be studied both in the field and laboratory. Furthermore, laboratory experiments on thermal impacts should adopt greater realism, incorporating diurnal temperature cycles in addition to investigating impacts of static temperatures. These may also benefit from adding in covarying factors such as day length, in case host/symbionts thermal behaviour has photoperiodic sensitivity. Furthermore, effects in a number of systems are known to be genotype dependent. Thus, prediction of dynamics may require a $\mathrm{G} \times \mathrm{G} \times \mathrm{E}$ framework. Finally, the impact of particular symbiont phenotypes of fitness (rather than their expression) is also likely to be thermally sensitive, and will require detailed examination of the wider ecological context in which the host exists. It is likely we will only get a predictive picture of thermal impacts when these aspects of natural environment complexity are incorporated.

The thermal sensitivity of heritable-microbe interactions begs two further questions. First, is host behaviour in terms of selecting thermal environments ever an adaptation to symbionts? Many organisms exhibit behavioural thermoregulation (Feder et al., 1997; Anderson et al., 2013). The possibility is that species carrying beneficial symbionts will be selected for temperature optima that cosset their symbionts, and may indeed be constrained in using behavioural fever as a means of curing pathogen infections. Reciprocally, presence of parasitic heritable symbionts may lead to selection for adopting temperatures that reduce the impact and transmission of the symbiont. Secondly, are the patterns of thermal impact on symbionts that we observe ever adaptive for the symbiont? Certain phenotypes (for example, natural enemy resistance) are only beneficial at particular times of year (when the natural enemy is active). If the expression of high titre to gain the phenotype is associated with a physiological cost, then titre may be expected to evolve as a thermally plastic trait of the symbiont, elevating only under the conditions present when the enemy is active. Microbial pathogens are well known to alter behaviour with temperature; for example, Listeria pathogenicity determinants are expressed at $37^{\circ} \mathrm{C}$ in association with ingestion by a mammal (Leimeister-Wächter et al., 1992). Thus, the machinery for microbial adaptive thermal plasticity clearly exists. Whether it is employed by heritable symbionts is an interesting question.

In conclusion, laboratory studies have revealed that symbiont presence may in part determine host thermal tolerance, and that many aspects of host-symbiont interactions are thermally sensitive such that thermal environment will likely alter the prevalence of heritable symbionts and the strength of phenotype observed in interactions. However, there commonly remains a research disconnect between laboratory measures and field dynamics. All laboratory measures in essence create hypotheses about how phenotype and transmission may be affected in the field, as the experimental study simplifies systems for purposes of experimental control. Furthermore, the ecological context will alter the benefits of particular phenotype in ways that are not easily predictable from the laboratory, but are likely to be thermally sensitive. These, and the degree to which thermal sensitivity is part of an adapted symbiosis, as opposed to an uncontrollable biological constraint, remain major questions for future research. 


\section{DATA ARCHIVING}

No data to deposit.

\section{CONFLICT OF INTEREST}

The authors declare no conflict of interest.

\section{ACKNOWLEDGEMENTS}

We thank Professor Andrew Fenton and members of the Adaptation to Environmental Change theme for providing comments on drafts of this manuscript, and three anonymous referees for helpful comments. This work was supported by a NERC studentship (to CC), a BBSRC studentship (to ERH) and NERC Grant NE/G003246/1 (to GDDH).

Afkhami ME, Rudgers JA (2008). Symbiosis lost: imperfect vertical transmission of fungal endophytes in grasses. Am Nat 172: 405-416.

Ahmed MZ, Araujo-Jnr EV, Welch JJ, Kawahara AY (2015). Wolbachia in butterflies and moths: geographic structure in infection frequency. Front Zool 12: 16.

Akman L, Yamashita A, Watanabe H, Oshima K, Shiba T, Hattori M et al. (2002). Genome sequence of the endocellular obligate symbiont of tsetse flies, Wigglesworthia glossinidia. Nat Genet 32: 402-407.

Anbutsu H, Goto S, Fukatsu T (2008). High and low temperatures differently affect infection density and vertical transmission of male-killing Spiroplasma symbionts in Drosophila hosts. App/ Environ Microbiol 74: 6053-6059.

Anderson RD, Blanford S, Thomas MB (2013). House flies delay fungal infection by fevering: at a cost. Ecol Entomol 38: 1-10.

Aschehoug ET, Metlen KL, Callaway RM, Newcombe G (2012). Fungal endophytes directly increase the competitive effects of an invasive forb. Ecology 93: 3-8.

Bandi C, Anderson TJ, Genchi C, Blaxter ML (1998). Phylogeny of Wolbachia in filarial nematodes. Proc Biol Sci 265: 2407-2413.

Baumann P (2005). Biology of bacteriocyte-associated endosymbionts of plant sap-sucking insects. Annu Rev Microbiol 59: 155-189.

Baumann P, Baumann L, Clark MA (1996). Levels of Buchnera aphidicola chaperonin GroEL during growth of the aphid Schizaphis graminum. Curr Microbiol 32: 279-285.

Bensadia F, Boudreault S, Guay J-F, Michaud D, Cloutier C (2006). Aphid clonal resistance to a parasitoid fails under heat stress. J Insect Physiol 52: 146-157.

Bordenstein SR, Bordenstein SR (2011). Temperature affects the tripartite interactions between bacteriophage WO, Wolbachia, and cytoplasmic incompatibility. PLoS One 6: e29106.

Bronikowski AM, Bennett AF, Lenski RE (2001). Evolutionary adaptation to temperature. Viii. Effects of temperature on growth rate in natural isolates of Escherichia Coli and Salmonella Enterica from different thermal environments. Evolution (NY) 55: 33-40.

Brumin M, Kontsedalov S, Ghanim M (2011). Rickettsia influences thermotolerance in the whitefly Bemisia tabaci B biotype. Insect Sci 18: 57-66.

Bryner SF, Rigling D (2011). Temperature dependent genotype-by-genotype interaction between a pathogenic fungus and its hyperparasitic virus. Am Nat 177: 65-74.

Burke G, Fiehn O, Moran N (2010). Effects of facultative symbionts and heat stress on the metabolome of pea aphids. ISME J 4: 242-252.

Burke GR, Moran NA (2011). Massive genomic decay in Serratia symbiotica, a recently evolved symbiont of aphids. Genome Biol Evol 3: 195-208.

Caragata EP, Rancès E, Hedges LM, Gofton AW, Johnson KN, O'Neill SL et al. (2013). Dietary cholesterol modulates pathogen blocking by Wolbachia. PLoS Pathog 9: e1003459.

Chen DQ, Montllor CB, Purcell AH (2000). Fitness effects of two facultative endosymbiotic bacteria on the pea aphid, Acyrthosiphon pisum, and the blue alfalfa aphid, A. kondoi. Entomol Exp App/ 95: 315-323.

Clancy DJ, Hoffmann AA (1998). Environmental effects on cytoplasmic incompatibility and bacterial load in Wolbachia-infected Drosophila simulans. Entomol Exp App/ 86: $13-24$

Clay K (1990). Fungal endophytes of grasses. Annu Rev Ecol Syst 21: 275-297.

Clay K, Holah J (1999). Fungal endophyte symbiosis and plant diversity in successional fields. Science 285: 1742-1744.

Clay K, Holah J, Rudgers JA (2005). Herbivores cause a rapid increase in hereditary symbiosis and alter plant community composition. Proc Natl Acad Sci USA 102: 12465-12470.

Clay K, Marks S, Cheplick GP (1993). Effects of insect herbivory and fungal endophyte infection on competitive interactions among grasses. Ecology 74: 1767-1777.

Counce SJ, Poulson DF (1966). The expression of maternally-transmitted sex ratio condition (SR) in two strains of Drosophila melanogaster. Genetica 37: 364-390.

Cowles HC (1915). Hereditary symbiosis. Bot Gaz 59: 61-63.

Cox P, Betts R, Jones C, Spall S, Totterdell I (2000). Acceleration of global warming due to carbon-cycle feedbacks in a coupled climate model. Nature 408: 184-187.

Darby AC, Armstrong SD, Bah GS, Kaur G, Hughes MA, Kay SM et al. (2012). Analysis of gene expression from the Wolbachia genome of a filarial nematode supports both metabolic and defensive roles within the symbiosis. Genome Res 22: 2467-2477.
Davitt AJ, Chen C, Rudgers JA (2011). Understanding context-dependency in plantmicrobe symbiosis: the influence of abiotic and biotic contexts on host fitness and the rate of symbiont transmission. Environ Exp Bot 71: 137-145.

de Souza DJ, Bézier A, Depoix D, Drezen J-M, Lenoir A (2009). Blochmannia endosymbionts improve colony growth and immune defence in the ant Camponotus fellah. BMC Microbiol 9: 29.

Dedeine F, Vavre F, Fleury F, Loppin B, Hochberg ME, Bouletreau M (2001). Removing symbiotic Wolbachia bacteria specifically inhibits oogenesis in a parasitic wasp. Proc Natl Acad Sci USA 98: 6247-6252.

Dixon AFG, Kindlmann P, Leps J, Holman J (1987). Why there are so few species of aphids, especially in the tropics. Am Nat 129: 580-592.

do Valle Ribeiro MAM (1993). Transmission and survival of Acremonium and the implications for grass breeding. Agric Ecosyst Environ 44: 195-213.

Douglas AE (2009). The microbial dimension in insect nutritional ecology. Funct Ecol 23: 38-47.

Dunbar HE, Wilson ACC, Ferguson NR, Moran NA (2007). Aphid thermal tolerance is governed by a point mutation in bacterial symbionts. PLoS Biol 5: 1006-1015.

Duron O, Bouchon D, Boutin S, Bellamy L, Zhou L, Engelstädter J et al. (2008). The diversity of reproductive parasites among arthropods: Wolbachia do not walk alone. BMC Bio/ 6: 27.

Ebbert MA, Nault LR (1994). Improved overwintering ability in Dalbulus maidis (Homoptera: Cicadellidae) vectors infected with Spiroplasma kunkelii (Mycoplasmatales: Spiroplasmataceae). Environ Entomol 23: 634-644.

Faeth SH, Fagan WF (2002). Fungal endophytes: common host plant symbionts but uncommon mutualists. Integr Comp Biol 42: 360-368.

Fan Y, Thompson JW, Dubois LG, Moseley MA, Wernegreen JJ (2013). Proteomic analysis of an unculturable bacterial endosymbiont (Blochmannia) reveals high abundance of chaperonins and biosynthetic enzymes. J Proteome Res 12: 704-718.

Feder ME, Blair N, Figueras H (1997). Oviposition site selection: unresponsiveness of Drosophila to cues of potential thermal stress. Anim Behav 53: 585-588.

Feder ME, Karr TL, Yang W, Hoekstra JM, James AC (1999). Interaction of Drosophila and its endosymbiont Wolbachia: natural heat shock and the overcoming of sexual incompatibility. Am Zool 39: 363-373.

Feldhaar H, Gross R (2009). Insects as hosts for mutualistic bacteria. Int J Med Microbiol 299: 1-8.

Fenton A, Johnson KN, Brownlie JC, Hurst GDD (2011). Solving the Wolbachia paradox: modeling the tripartite interaction between host, Wolbachia, and a natural enemy. Am Nat 178: 333-342.

Fine PE (1975). Vectors and vertical transmission: an epidemiologic perspective. Ann NY Acad Sci 266: 173-194.

Gibson CM, Hunter MS (2010). Extraordinarily widespread and fantastically complex: comparative biology of endosymbiotic bacterial and fungal mutualists of insects. Ecol Lett 13: 223-234.

Girin C, Boulétreau M (1995). Microorganism-associated variation in host infestation efficiency in a parasitoid wasp,Trichogramma bourarachae (Hymenoptera: Trichogrammatidae). Experientia 51: 398-401.

Grill LK, Garger SJ (1981). Identification and characterization of double-stranded RNA associated with cytoplasmic male sterility in Vicia faba. Proc Natl Acad Sci USA 78: 7043-7046.

Guay J-F, Boudreault S, Michaud D, Cloutier C (2009). Impact of environmental stress on aphid clonal resistance to parasitoids: role of Hamiltonella defensa bacterial symbiosis in association with a new facultative symbiont of the pea aphid. J Insect Physiol 55: 919-926.

Gundel PE, Batista WB, Texeira M, Martínez-Ghersa MA, Omacini M, Ghersa CM (2008). Neotyphodium endophyte infection frequency in annual grass populations: relative importance of mutualism and transmission efficiency. Proc Biol Sci 275: 897-905.

Gundel PE, Rudgers JA, Ghersa CM (2011). Incorporating the process of vertical transmission into understanding of host-symbiont dynamics. Oikos 120: 1121-1128.

Hansen AK, Moran NA (2011). Aphid genome expression reveals host-symbiont cooperation in the production of amino acids. Proc Natl Acad Sci USA 108: 2849-2854.

Harmon JP, Moran NA, Ives AR (2009). Species response to environmental change: impacts of food web interactions and evolution. Science 323: 1347-1350.

Haselkorn TS (2010). Understanding the Distribution of the Spiroplasma Heritable Bacterial Symbiont in Drosophila. University of California: San Diego.

Heddi A, Grenier A-M, Khatchadourian C, Charles H, Nardon P (1999). Four intracellular genomes direct weevil biology: nuclear, mitochondrial, principal endosymbiont, and Wolbachia. Proc Natl Acad Sci USA 96: 6814-6819.

Heyworth ER, Ferrari J (2015). A facultative endosymbiont in aphids can provide diverse ecological benefits. J Evol Biol 28: 1753-1760.

Hoffmann AA, Turelli M, Simmons GM (1986). Unidirectional incompatibility between populations of Drosophila simulans. Evolution (NY) 40: 692-701.

Hosokawa T, Hironaka M, Mukai H, Inadomi K, Suzuki N, Fukatsu T (2012). Mothers never miss the moment: a fine-tuned mechanism for vertical symbiont transmission in a subsocial insect. Anim Behav 83: 293-300.

Hosokawa T, Kikuchi Y, Nikoh N, Shimada M, Fukatsu T (2006). Strict host-symbiont cospeciation and reductive genome evolution in insect gut bacteria. PLOS Bio/ 4: e337.

Hubbard M, Germida J, Vujanovic V (2012). Fungal endophytes improve wheat seed germination under heat and drought stress. Botany 90: 137-149.

Hurst GDD, Frost CL (2015). Reproductive parasitism: maternally inherited symbionts in a biparental world. Cold Spring Harb Perspect Biol 7: a017699.

Hurst GDD, Jiggins FM, Robinson SJW (2001). What causes inefficient transmission of male-killing Wolbachia in Drosophila? Heredity (Edinb) 87: 220-226. 
Hurst GDD, Johnson AP, Fuyama Y (2000). Male-killing Wolbachia in Drosophila: a temperature-sensitive trait with a threshold bacterial density. Genetics 156: 699-709.

Hyder R, Pennanen T, Hamberg L, Vainio EJ, Piri T, Hantula J (2013). Two viruses of Heterobasidion confer beneficial, cryptic or detrimental effects to their hosts in different situations. Fungal Ecol 6: 387-396.

Jaenike J (2009). Coupled population dynamics of endosymbionts within and between hosts. Oikos 118: 353-362.

Jia F-X, Yang M-S, Yang W-J, Wang J-J (2009). Influence of continuous high temperature conditions on Wolbachia infection frequency and the fitness of Liposcelis tricolor (Psocoptera: Liposcelididae). Environ Entomol 38: 1365-1372.

Johanowicz DL, Hoy MA (1998). Experimental induction and termination of non-reciprocal reproductive incompatibilities in a parahaploid mite. Entomol Exp App/ 87: 51-58.

Kageyama D, Anbutsu H, Watada M, Hosokawa T, Shimada M, Fukatsu T (2006) Prevalence of a non-male-killing spiroplasma in natural populations of Drosophila hydei. Appl Environ Microbiol 72: 6667-6673.

Kellner RLL (2002). Molecular identification of an endosymbiotic bacterium associated with pederin biosynthesis in Paederus sabaeus (Coleoptera: Staphylinidae). Insect Biochem Mol Biol 32: 389-395.

Koehler S, Kaltenpoth M (2013). Maternal and environmental effects on symbiontmediated antimicrobial defense. J Chem Ecol 39: 978-988.

Koga R, Tsuchida T, Fukatsu T (2003). Changing partners in an obligate symbiosis: a facultative endosymbiont can compensate for loss of the essential endosymbiont Buchnera in an aphid. Proc $R$ Soc B Biol Sci 270: 2543-2550.

Koga R, Tsuchida T, Sakurai M, Fukatsu T (2007). Selective elimination of aphid endosymbionts: Effects of antibiotic dose and host genotype, and fitness consequences. FEMS Microbiol Ecol 60: 229-239.

Kriesner P, Conner WR, Weeks AR, Turelli M, Hoffmann AA (2016). Persistence of Wolbachia infection frequency cline in Drosophila melanogaster and the possible role of reproductive dormancy. Evolution (NY) 70: 979-997.

L'Heritier PH (1970). Drosophila viruses and their role as evolutionary factors. Evol Biol 4 185-209.

Leimeister-Wächter M, Domann E, Chakraborty T (1992). The expression of virulence genes in Listeria monocytogenes is thermoregulated. J Bacteriol 174: 947-952.

Liu S, Chougule NP, Vijayendran D, Bonning BC (2012). deep sequencing of the transcriptomes of soybean aphid and associated endosymbionts. PLoS One 7 e45161.

Longdon B, Brockhurst MA, Russell CA, Welch JJ, Jiggins FM (2014). The evolution and genetics of virus host shifts. PLoS Pathog 10: e1004395.

Longdon B, Wilfert L, Jiggins FM (2012). The sigma viruses of Drosophila. In: Ralf D, Ivan K (eds), Rhabdoviruses: Molecular Taxonomy, Evolution, Genomics, Ecology, Cytopathology and Control. Caister Academic Press: Poole, UK, pp 117-132.

Łukasik P, Hancock EL, Ferrari J, Godfray HCJ (2011). Grain aphid clones vary in frost resistance, but this trait is not influenced by facultative endosymbionts. Ecol Entomol 36: 790-793.

Malogolowkin C (1959). Temperature effects on maternally inherited ' sex-ratio ' conditions in Drosophila willistoni and Drosophila equinoxialis. Am Nat 93: 365-368.

Márquez LM, Redman RS, Rodriguez RJ, Roossinck MJ (2007). A virus in a fungus in a plant: three-way symbiosis required for thermal tolerance. Science 315: 513-515.

McMeniman CJ, Lane RV, Cass BN, Fong AW, Sidhu M, Wang Y-F et al. (2012). Stable introduction of a life-shortening Wolbachia infection into the mosquito Aedes aegypti. Science 323: 141-144.

Min KT, Benzer S (1997). Wolbachia, normally a symbiont of Drosophila, can be virulent, causing degeneration and early death. Proc Natl Acad Sci USA 94: 10792-10796.

Montenegro H, Hatadani LM, Medeiros HF, Klaczko LB (2006). Male killing in three species of the tripunctata radiation of Drosophila (Diptera: Drosophilidae). J Zool Syst Evol Res 44: 130-135.

Montenegro H, Klaczko LB (2004). Low temperature cure of a male killing agent in Drosophila melanogaster. J Invertebr Patho/ 86: 50-51.

Montenegro H, Solferini VN, Klaczko LB, Hurst GDD (2005). Male-killing Spiroplasma naturally infecting Drosophila melanogaster. Insect Mol Biol 14: 281-287.

Montllor CB, Maxmen A, Purcell AH (2002). Facultative bacterial endosymbionts benefit pea aphids Acyrthosiphon pisum under heat stress. Ecol Entomol 27: 189-195.

Morag N, Klement E, Saroya Y, Lensky I, Gottlieb Y (2012). Prevalence of the symbiont Cardinium in Culicoides (Diptera: Ceratopogonidae) vector species is associated with land surface temperature. FASEB J 26: 4025-4034.

Moran NA (1996). Accelerated evolution and Muller's rachet in endosymbiotic bacteria. Proc Natl Acad Sci USA 93: 2873-2878.

Moran NA, Dunbar HE (2006). Sexual acquisition of beneficial symbionts in aphids. Proc Natl Acad Sci USA 103: 12803-12806.

Moran NA, Yun Y (2015). Experimental replacement of an obligate insect symbiont. Proc Natl Acad Sci USA 112: 2093-2096.

Mueller UG, Mikheyev AS, Hong E, Sen R, Warren DL, Solomon SE et al. (2011). Evolution of cold-tolerant fungal symbionts permits winter fungiculture by leafcutter ants at the northern frontier of a tropical ant-fungus symbiosis. Proc Natl Acad Sci USA 108 4053-4056.

Murdock CC, Blanford S, Hughes GL, Rasgon JL, Thomas MB (2014). Temperature alters Plasmodium blocking by Wolbachia. Sci Rep 4: 3932.

Nakabachi A, Ueoka R, Oshima K, Teta R, Mangoni A, Gurgui M et al. (2013) Defensive bacteriome symbiont with a drastically reduced genome. Curr Biol 23 $1478-1484$

Neelakanta G, Sultana H, Fish D, Anderson JF, Fikrig E (2010). Anaplasma phagocytophilum induces Ixodes scapularis ticks to express an antifreeze glycoprotein gene that enhances their survival in the cold. J Clin Invest 120: 3179-3190.
Nikoh N, Hosokawa T, Oshima K, Hattori M, Fukatsu T (2011). Reductive evolution of bacterial genome in insect gut environment. Genome Biol Evol 3: 702-714.

O'Fallon B (2008). Population structure, levels of selection, and the evolution of intracellular symbionts. Evolution (NY) 62: 361-373.

Oldrup E, McLain-Romero J, Padilla A, Moya A, Gardner D, Creamer R (2010). Localization of endophytic fungi in locoweed seed and influence of environmental parameters on a locoweed in vitro culture system. Botany 88: 512-521.

Oliver KM, Moran NA, Hunter MS (2005). Variation in resistance to parasitism in aphids is due to symbionts not host genotype. Proc Natl Acad Sci USA 102: $12795-12800$.

Olsen K, Reynolds KT, Hoffmann AA (2001). A field cage test of the effects of the endosymbiont Wolbachia on Drosophila melanogaster. Heredity (Edinb) 86 731-737.

Osaka R, Nomura M, Watada M, Kageyama D (2008). Negative effects of low temperatures on the vertical transmission and infection density of a spiroplasma endosymbiont in Drosophila hydei. Curr Microbiol 57: 335-339.

Parish WEG, Bale JS (1991). Effect of low temperatures on the intracellular symbionts of the grain aphid Sitobion avenae (F.) (Hem., Aphididae). J Insect Physiol 37: 339-345.

Parkinson JF, Gobin B, Hughes WOH (2014). Short-term heat stress results in diminution of bacterial symbionts but has little effect on life history in adult female citrus mealybugs. Entomol Exp App/ 153: 1-9.

Parmesan C, Yohe G (2003). A globally coherent fingerprint of climate change impacts across natural systems. Nature 421: 37-42.

Pastok D (2015). Causes of Spatial Variation in Parasite and Pathogen Pressure In insects. $\mathrm{PhD}$ thesis, University of Liverpool.

Patiño-Navarrete R, Moya A, Latorre A, Peretó J (2013). Comparative genomics of Blattabacterium cuenoti: the frozen legacy of an ancient endosymbiont genome. Genome Biol Evol 5: 351-361.

Pérez-Brocal V, Gil R, Ramos S, Lamelas A, Postigo M, Michelena JM et al. (2006). A small microbial genome: the end of a long symbiotic relationship? Science 314: 312-313.

Perrot-Minnot MJ, Guo LR, Werren JH (1996). Single and double infections with Wolbachia in the parasitic wasp Nasonia vitripennis: Effects on compatibility. Genetics 143 961-972.

Pintureau B, Chapelle L, Delobel B (1999). Effects of repeated thermic and antibiotic treatments on a Trichogramma (Hym., Trichogrammatidae) symbiont. J App/ Entomol 123: 473-483.

Poinar GO (1975). Description and biology of a new insect parasitic rhabditoid, Heterorhabditis bacteriophora n. gen., n. sp. (Rhabditida: Heterorhabditidae n. fam.). Nematologica 21: 463-470.

Polin S, Simon J-C, Outreman Y (2014). An ecological cost associated with protective symbionts of aphids. Ecol Evol 4: 836-840.

Pool JE, Wong A, Aquadro CF (2006). Finding of male-killing Spiroplasma infecting Drosophila melanogaster in Africa implies transatlantic migration of this endosymbiont. Heredity (Edinb) 97: 27-32

Redman RS, Sheehan KB, Stout RG, Rodriguez RJ, Henson JM (2002). Thermotolerance generated by plant/fungal symbiosis. Science 298: 1581 .

Reynolds KT, Thomson LJ, Hoffmann AA (2003). The effects of host age, host nuclear background and temperature on phenotypic effects of the virulent wolbachia strain popcorn in Drosophila melanogaster. Genetics 164: 1027-1034.

Rodriguez RJ, Henson J, Van Volkenburgh E, Hoy M, Wright L, Beckwith F et al. (2008). Stress tolerance in plants via habitat-adapted symbiosis. ISME J 2: 404-416.

Rodriguez R, Redman R (2008). More than 400 million years of evolution and some plants still can't make it on their own: plant stress tolerance via fungal symbiosis. J Exp Bot 59: 1109-1114.

Rodriguez RJ, White JF, Arnold AE, Redman RS (2009). Fungal endophytes: diversity and functional roles. New Phytol 182: 314-330.

Roossinck MJ (2015). Move over bacteria! Viruses make their mark as mutualistic microbial symbionts. J Virol 89: 6532-6535.

Russell JA, Moran NA (2006). Costs and benefits of symbiont infection in aphids: variation among symbionts and across temperatures. Proc R Soc B Biol Sci 273: 603-610.

Sacchi L, Grigolo A, Biscaldi G, Laudani U (1993). Effects of heat treatment on the symbiotic system of Blattoidea: morphofunctional alterations of bacteriocytes. Ital J Zool 60: 271-279.

Sakamoto H, Kageyama D, Hoshizaki S, Ishikawa Y (2008). Heat treatment of the Adzuki bean borer, Ostrinia scapulalis infected with wolbachia gives rise to sexually mosaic offspring. J Insect Sci 8: 1-5.

Scarborough CL, Ferrari J, Godfray HCJ (2005). Aphid protected from pathogen by endosymbiont. Science 310: 1781 .

Sheeley SL, McAllister BF (2009). Mobile male-killer: similar Wolbachia strains kill males of divergent Drosophila hosts. Heredity (Edinb) 102: 286-292.

Shigenobu S, Stern DL (2013). Aphids evolved novel secreted proteins for symbiosis with bacterial endosymbiont. Proc Biol Sci 280: 20121952.

Slatko BE, Taylor MJ, Foster JM (2010). The Wolbachia endosymbiont as an anti-filarial nematode target. Symbiosis 51: 55-65.

Stevens L (1989). Environmental factors affecting reproductive incompatibility in flour beetles, genus Tribolium. J Invertebr Pathol 53: 78-84.

Stouthamer R, Luck RF, Hamilton WD (1990). Antibiotics cause parthenogenetic Trichogramma (Hymenoptera/Trichogrammatidae) to revert to sex. Proc Natl Acad Sc USA 87: 2424-2427.

Sugimoto TN, Kayukawa T, Matsuo T, Tsuchida T, Ishikawa Y (2015). A short, hightemperature treatment of host larvae to analyze Wolbachia-host interactions in the moth Ostrinia scapulalis. J Insect Physiol 81: 48-51. 
Thomas MB, Blanford S (2003). Thermal biology in insect-parasite interactions. Trends Ecol Evol 18: 344-350.

Tinsley MC (2003). The Ecology and Evolution of Male-Killing Bacteria in Ladybirds. University of Cambridge.

Toju H, Fukatsu T (2011). Diversity and infection prevalence of endosymbionts in natural populations of the chestnut weevil: relevance of local climate and host plants. $\mathrm{Mol} \mathrm{Ecol}$ 20: 853-868.

Trpis M, Perrone JB, Reissig M (1981). Control of cytoplasmic incompatibility in the Aedes scutlelaris complex. J Hered 72: 313-317.

Tsuchida T, Koga R, Shibao H, Matsumoto T, Fukatsu T (2002). Diversity and geographic distribution of secondary endosymbiotic bacteria in natural populations of the pea aphid, Acyrthosiphon pisum. Mol Ecol 11: 2123-2135.

Unckless RL, Jaenike J (2012). Maintenance of a male-killing Wolbachia in Drosophila innubila by male-killing dependent and male-killing independent mechanisms. Evolution (NY) 66: 678-689.

van Ham RCHJ, Kamerbeek J, Palacios C, Rausell C, Abascal F, Bastolla U et al. (2003). Reductive genome evolution in Buchnera aphidicola. Proc Natl Acad Sci USA 100 581-586.

van Opijnen T, Breeuwer JA (1999). High temperatures eliminate Wolbachia, a cytoplasmic incompatibility inducing endosymbiont, from the two-spotted spider mite. Exp Appl Acarol 23: 871-881.

Versace E, Nolte V, Pandey RV, Tobler R, Schlötterer C (2014). Experimental evolution reveals habitat-specific fitness dynamics among Wolbachia clades in Drosophila melanogaster. $\mathrm{Mol}$ Ecol 23: 802-814.

Vorburger C, Ganesanandamoorthy P, Kwiatkowski M (2013). Comparing constitutive and induced costs of symbiont-conferred resistance to parasitoids in aphids. Ecol Evol 3: 706-713.
Walther G, Post E, Convey P, Menzel A, Parmesan C, Beebee TJC et al. (2002). Ecological responses to recent climate change. Nature 416: 389-395.

Watanabe K, Yukuhiro F, Matsuura Y, Fukatsu T, Noda H (2014). Intrasperm vertical symbiont transmission. Proc Natl Acad Sci USA 111: 7433-7437.

Wernegreen JJ (2002). Genome evolution in bacterial endosymbionts of insects. Nat Rev Genet 3: 850-861.

Werren JH, Baldo L, Clark ME (2008). Wolbachia: master manipulators of invertebrate biology. Nat Rev Microbiol 6: 741-751.

Wilcox JL, Dunbar HE, Wolfinger RD, Moran NA (2003). Consequences of reductive evolution for gene expression in an obligate endosymbiont. Mol Microbiol 48: $1491-1500$.

Williamson DL (1965). Kinetic studies of 'sex ratio' spirochetes in Drosophila melanogaster Meigen females. J Invertebr Pathol 7: 493-501.

Williamson DL, Poulson DF (1979). Sex ratio organisms (spiroplasmas) of Drosophila. In: Whitcomb RF, Tully JG (eds), The Mycoplasmas, vol. 3, pp 175-208.

Wright JD, Wang BT (1980). Observations on wolbachiae in mosquitoes. J Invertebr Pathol 35: 200-208.

Xie J, Vilchez I, Mateos M (2010). Spiroplasma bacteria enhance survival of Drosophila hydei attacked by the parasitic wasp Leptopilina heterotoma. PLoS One 5: e12149.

Ye YH, Carrasco AM, Dong Y, Sgro CM, McGraw EA (2016). The effect of temperature on Wolbachia-mediated dengue virus blocking in Aedes aegypti. Am J Trop Med Hyg 94: 812-819.

Zientz E, Dandekar T, Gross R (2004). Metabolic interdependence of obligate intracellular bacteria and their insect hosts. Microbiol Mol Biol Rev 68: 745-770.

Zug R, Koehncke A, Hammerstein P (2012). Epidemiology in evolutionary time: the case of Wolbachia horizontal transmission between arthropod host species. J Evol Biol 25: 2149-2160. 